\title{
Moving across physical and online spaces: a case study in a blended primary classroom
}

\section{Patricia Thibaut, Jen Scott Curwood, Lucila Carvalho \& Alyson Simpson}

To cite this article: Patricia Thibaut, Jen Scott Curwood, Lucila Carvalho \& Alyson Simpson (2015) Moving across physical and online spaces: a case study in a blended primary classroom, Learning, Media and Technology, 40:4, 458-479, DOI: 10.1080/17439884.2014.959971

To link to this article: http://dx.doi.org/10.1080/17439884.2014.959971

\section{Published online: 06 Oct 2014.}

\section{Submit your article to this journal $\left[\begin{array}{c} \\ \mathrm{C}\end{array}\right.$}

Џلll Article views: 189

Q View related articles $\sqsubset$

View Crossmark data ¿ 


\title{
Moving across physical and online spaces: a case study in a blended primary classroom
}

\author{
Patricia Thibaut*, Jen Scott Curwood*, Lucila Carvalho and Alyson Simpson \\ Faculty of Education and Social Work, The University of Sydney, Education \\ Building A35, Sydney, NSW 2006, Australia
}

(Received 26 May 2014; accepted 26 August 2014)

\begin{abstract}
With the introduction of digital tools and online connectivity in primary schools, the shape of teaching and learning is shifting beyond the physical classroom. Drawing on the architecture of productive learning networks framework, we examine the affordances and limitations of an upper primary learning network and focus on how the digital and physical elements involved in set design shape teachers' pedagogical approaches and students' learning processes. The findings suggest that blended spaces support teachers' distributed orchestration of classroom activities across tools and resources while also leveraging students' engagement in reciprocal teaching and collaborative learning.
\end{abstract}

Keywords: blended learning; primary education; technology; productive learning network; pedagogy

\section{Introduction}

Technology is pervasive in our modern lives. Research shows that it is integral to content creation, social interaction, information acquisition, collaboration, and communication (Lenhart et al. 2007, 2010). In light of technological innovations, schools are increasingly adopting digital tools and promoting online spaces for learning. However, educational research needs to further explore how to effectively design educational tasks and how to productively use blended spaces. Even though blended learning has been a growing topic of research in higher education over the last decade (Sharpe, Benfield, and Roberts 2006; Bliuc et al. 2011; Means, Murphy, and Baki 2013), research on blended learning in primary and secondary education has been less studied (Picciano 2009).

To address this gap, the present study explores the use of physical and digital technologies in a blended environment through a case study of an Australian upper primary classroom. The space we examined includes a physical space

\footnotetext{
*Corresponding authors. Emails: patricia.thibautpaez@sydney.edu.au; js.curwood@ sydney.edu.au 
where students and teachers interact in conventional face-to-face modes and an online space where students engage in asynchronous interactions. We use the architecture of productive learning networks (Carvalho and Goodyear 2014) framework in order to examine relationships among students' learning activities, teachers' instruction, and the spaces, tools, and resources they interact with in the classroom. We claim that in a technology-saturated era, such research is necessary due to the potential opportunities that new tools create for teaching and learning. Computers, mobile phones, iPads, digital games, social media tools, discussion boards, and websites, among others, are relatively new elements that are rapidly permeating classroom spaces. In this paper, we posit that teaching and learning are mediated across agents, tools, and spaces (Hewitt and Scardamalia 1998; Hutchins 2000). We focus specifically on the relational activities between and across students, teachers, tools, and blended spaces in a primary classroom.

Research into the role of physical and digital spaces in learning settings not only involves thinking about agents, tools, and the layout of those environments but also implies understanding how those factors come into play, interact, connect, and interfere with one another during learning events. Our study was guided by the following research questions:

- How are teachers' practices shaped in a blended classroom?

- What are teachers' perceptions of technology integration in a blended classroom?

- How do teachers' practices influence students' activities in a blended classroom?

Our analysis of teaching and learning takes an activity-centred approach, emphasising the relational aspect of agents (the students and the teachers) and the digital and physical classroom resources. By using an activitycentred unit of study, we look at the intersection between agents and objects, and the activities and actions that evidence the relational aspect of elements, agents, and the learning and teaching practices in a physical and in an online space.

In the following sections, we briefly contextualise what is understood by blended learning and explain how the architecture of productive learning networks approach supported our analysis of activities and interactions between agents and tools across multiple spaces. We then consider how material and digital elements in the online and physical spaces are related to particular ways of teaching and learning. Finally, we discuss the implications of our research and suggest ways that educators may capitalise on the affordances of blended spaces, specifically by using material and digital elements to support students' learning and teachers' practices at the primary school level. 


\section{Theorising space and matter in teaching and learning}

We refer to the combination of physical and digital spaces as blended spaces for learning; in prior research, it has also been referred to as hybrid, mixed, virtual, or e-learning (Sharpe, Benfield, and Roberts 2006). It is important to note that despite the changes provoked by digital technologies in today's educational settings, there are examples and patterns of best practices pursued by innovative schools documented since the beginning of last century that need to be taken into account (Burke, Cunningham, and Grosvenor 2010; Burke and Grosvenor 2013; Burke 2014). We attempt to bring current research on teaching and learning with past experiences of school practices by drawing on a networked learning approach. The architecture of productive learning networks framework allows us to investigate materiality, agents, and tools that underpin activities within a complex learning environment (Goodyear 2005; Carvalho and Goodyear 2014). We argue that examining issues related to the spatial dimension of learning requires a lens through which both agent and space can be taken into account, thereby becoming visible as units of study (Barron 2006). Our focus is on the influence of physical and digital elements on learners and instructional activities as well as their connections to other social and epistemic elements in complex learning environments.

Goodyear et al. (2004) define networked learning as 'learning in which ICT is used to promote connections: between one learner and other learners; between learners and tutors; between a learning community and its learning resources' (83). The term connection acknowledges the relational elements in a learning environment that includes media and technology. Building on these ideas, Goodyear and Carvalho (2014) suggest the use of an architectural framework for the analysis of learning networks. This framework includes four main components: (1) physical architecture (set design), which includes physical and online spaces along with physical and digital tools, including pens, notebooks, computers, iPads, and other resources; (2) epistemic architecture (epistemic design), which refers to two dimensions: a macro level related to knowledge, ways of knowing, and types of knowledge along with a micro level including the design of tasks and subtasks; (3) social architecture (social design), which relates to social interactions and division of labour; (4) the co-creation and co-configuration activities, which acknowledges that learners and teachers may re-configure what has been designed (Carvalho and Goodyear 2014).

By highlighting the relational nature of the physical, epistemic, and social elements designed in a learning environment and the activities that learners engage with in such an environment, the framework supports our investigation of how space and elements in a classroom may shape students' learning activities and teachers' instructional practices. The framework differentiates tasks and activity: a task is what the teacher designs for students to do, whereas an activity refers to what students actually do. In other words, it is the enactment 
of the task by the learners, which may differ widely from the former (Goodyear 2005).

In this paper, we focus on the concept of activity as it relates to elements in the set design, rather than tasks (or epistemic design), in order to examine what students do in relation to the digital and physical elements of the classroom. In this regard, we take the view that teaching and learning are situated and indexed in activities (Brown, Collins, and Duguid 1989); therefore, we believe that activities represent ways of teaching and learning. By examining activities of students and teachers within a networked learning perspective, we attempt to seek evidence of the nature of teaching and learning practices in the classroom. In future research, we will explore the alignment between task design and the activities of students in the classroom.

From a network perspective, a learning environment is seen as 'the shared habitat of a collection of learners' (Goodyear 2000, 2). Drawing on a Networked Learning model eliminates the risk of an unidirectional analysis where particular tools, sets, or pedagogies are considered in isolation and where affordances or limitations are mistakenly attributed to discrete elements in the environment, without acknowledging that they coexist in a multidimensional habitat, or learning space. Such a networked learning perspective supports our view on the articulation of elements in the classroom and the pivotal role of set design in the plan of tasks, selection of pedagogies, enactments of activities, and ultimately, in students' learning. Figure 1 illustrates

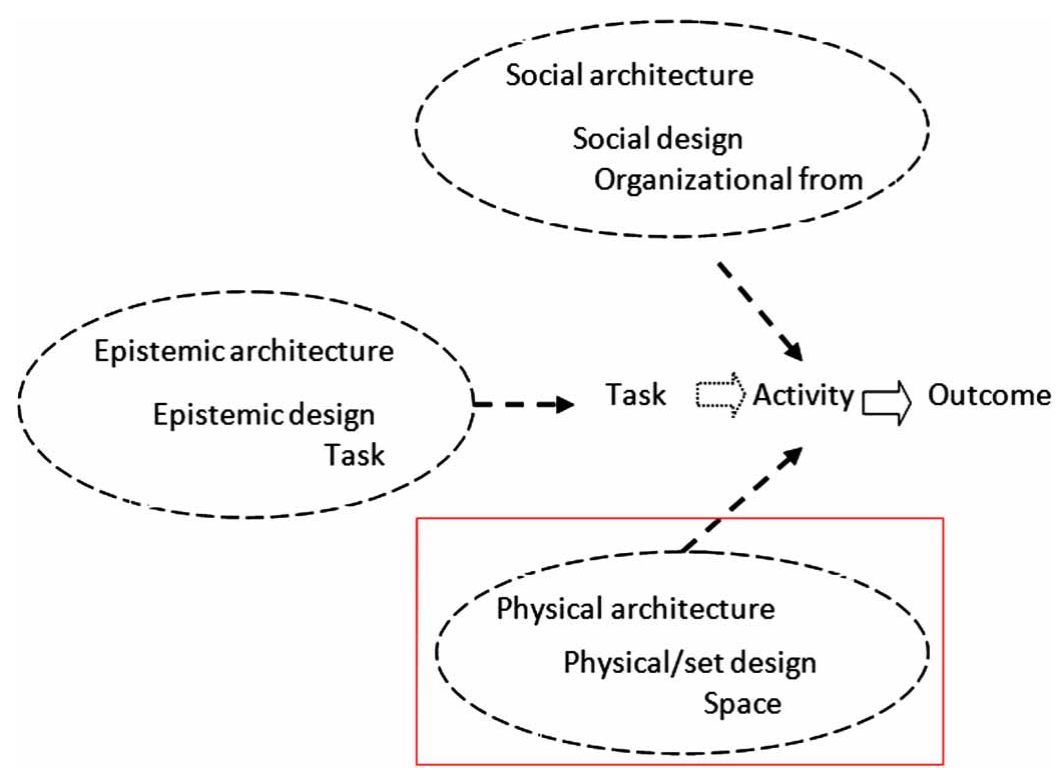

Figure 1. Set, epistemic and social co-creation and co-configuration activities. Source: Modified from Goodyear and Carvalho (2014). 
the connections between set, epistemic, and social architectures and their influence on learning activities.

\section{Methodology}

\subsection{Study context}

The study was conducted in a K-12 independent faith-based school in Sydney, Australia, with a total enrolment of 1200 students. Approximately three-quarters of students in this school continue on to tertiary education. Over the last decade, the school has gained a marked reputation for technology integration in the classroom, innovative professional development for teachers, and a focus on modern learning spaces. As in most case study research, generalisability may be limited; our aim here is to offer an in-depth description of a new generation learning space and consider its implications for teaching and learning.

The learning space in this study is not conventional. It comprises a large open plan environment that accommodates six combined classes from years five and six, with a total of approximately 180 students and six to eight teachers. Originally it was structured as six conventional classroom spaces, with their respective walls and fixed white boards, yet as part of recent infrastructural and pedagogical reforms, the layout of the school shifted from isolated classrooms with closed boundaries to an open plan with collaborative spaces. A detailed analysis of the learning space is provided in the findings section.

\subsection{Participants}

Participants in the study included a class of 30 students in year six and the teachers with whom they interact. We included all six teachers in this study as teachers work collaboratively and normally teach in pairs in the large open learning space. We offer a more detailed description of the head teacher in this class, as she was the designer and main instructional participant of the project we give account of in this study. At the time of the study, Claire (a pseudonym) had 11 years of teaching experience. She described herself as a techsavvy teacher who was passionate about exploring new forms of instruction with the use of technology. She pointed out that by using social media tools such as Twitter and blogs, she stayed current with the use of technology in the classroom. Claire also emphasised that professional development in her school has played an important role in her understanding and application of technology in the classroom.

Students participating in the study were all in the same class and between 11 and 12 years old, including 10 girls and 20 boys. In relation to technology, each student had his/her own personal digital device in accordance with the school's Bring Your Own Device (BYOD) policy. Students reported high levels of 
technology competence and were skilful in navigating various interfaces required for class activities.

\subsection{Learning task: the theme park project}

The theme park project was a four-week long project designed by Claire as part of a term's work activity that involved an integrated inquiry approach that supplemented and connected literacy and numeracy content across years five and six. The theme park project involved two phases. The first phase included students investigating the history and development of theme parks around the world. In the second phase, students were asked to prepare three main outputs: (a) a PowerPoint or Prezi presentation about a specific theme park, displaying some of the major attractions, explaining the reasons for closure and three lessons learnt from the park's closure; (b) a scale theme park design using digital applications such as Google SketchUp or physical materials such as cardboard and paint; and (c) an 'Australiana' theme park concept website. The rubric given to the students as a guide to develop their project included the following elements: (1) theme park name; (2) logo; (3) catch phrase; (4) vision statement; (5) indigenous considerations; (6) inclusive considerations; (7) Christianity in action.

\subsection{Data collection}

The data collection was part of a larger case study that aimed to examine the interplay between literacy, technology, and learning. We collected data in the field over a period of three terms during the 2013 school year; we also collected data from the Edmodo online space through the fourth term. This allowed us to have a longitudinal perspective of the interactions occurring in the online space. Data collected in the classroom field included 125 hours of videotaped classroom observations; field notes, including events related to students' interactions and teachers' pedagogy; a survey that examined students' school motivation and technology usage; eight in-depth interviews with students and six interviews with teachers regarding technology and literacy; one interview with the principal of the school about school culture, technology, and literacy; and a collection of physical and digital artefacts designed by the students.

For the present analysis of the interplay between blended spaces and teachers' and students' practices, we focus on the data collected during the development of the four-week theme park project. This includes the interviews with teachers and students; the recording of students' physical artefacts captured through photographs and the collection of students' digital artefacts captured through screenshots of their websites and Google SketchUp final products; video recording of students' mid and final presentations; and students' entries, including the activities and communication that students and the teacher enacted on the Edmodo wall. 


\subsection{Data analysis}

In order to provide an understanding of students' and teachers' practices across digital and physical spaces, we borrowed from the Networked Learning model. While we examined the data through the lenses of the set design, the analysis also included the epistemic and social aspects as well as the co-creation and co-configuration as they are constitutive elements of the architectural framework of networked learning and, consequently, intimately related to the set design (Carvalho and Goodyear 2014). A Networked Learning model gives us the structure to examine teaching and learning practices; however, it says little about how to capture in detail the events and activities enacted across the set, epistemic, and social designs. For that purpose, we draw on Biggs and Tang (2007) and their concept of activity-centred position. This concept shares similarities with Wertsch's (1998) notion about agents acting through 'mediated means' such as language, mathematic symbolic system, figures, maps (Vygotsky 1981). Biggs and Tang (2007) focus particularly on the actions that the agents do, moving forward the examination of just tools, and instead, seeing value in the activities that agents enact with the affordances of the tools available in the blended space.

Data analysis involved tracing the activities of students and teacher across the digital and the physical spaces and coding them according to the Networked Learning model. This involved the analysis of various data sets, particularly the observations and the video recordings conducted by the researchers during the field work, the recordings of students' interactions on Edmodo, and students' production of tasks' outputs on digital and physical mediums. In particular, we employed an inductive approach to video analysis to find patterns across events in the complex learning environment of the classroom and as a way to provide evidence for narrative interpretation of the present case study (Mehan 1979; Barron 2003; Derry et al. 2010). Data analysis also included the revision and alignment of evidence of activities across the physical and the digital space through the use of NVivo software.

In order to gain a better understanding and contextualise the data gathered by observations in the physical classroom and the digital space, we triangulated the data with interviews with teachers and students. At this point of the analysis, we knew the types of activities the teacher and students were engaged in, the types of tools selected in those activities, and the type of navigation that students and teacher were enacting across the physical and the digital environment. The next step in our inquiry was to complement this with less tangible evidence about the perceptions of the agents in this environment. We applied a thematic analysis method to look for evidence about the underlying meanings of learning and teaching processes that integrated technology from the agents' point of view. In particular, the interviews were transcribed and analysed and the emerging themes were identified and discussed, which led to the refinement of categories (Attride-Stirling 2001). Through the analysis of interviews with students and 
teachers, we were able to account for the perceptions and the meanings that the agents in the space give to their activities in this blended environment.

\section{Findings and discussion}

Through the analysis of the learning activities, blended contexts, and mediated actions of 30 students and their teachers, we were able to identify and highlight the role that space and elements in the space have in a particular class. We begin by describing the set design that students and teachers used during the project. Next, we examine the teacher's practices in the context of a blended environment. Finally, we connect those activities with the perceptions of the agents about technological tools and the influence on students' learning activities.

\subsection{Understanding the set design}

\subsubsection{Physical space}

The set design analysed in this study consists of both a physical and a digital space. The physical space has two floors and a wide staircase that connects the two areas of the large open plan environment. The physical, or material, space of the classroom includes large and A4-sized whiteboards, two project screens, one in each level of the plan, and walls that function as a canvas for writing, drawing, and sketching. Tools available in the space include students' and teacher's laptops, notepads, pens, and paper. The furniture in the space combined conventional elements of a classroom environment such as seats and tables along with less traditional furniture such as bean bags, laptop trays, rugs, and power points to allow students to work on the floor.

During the theme park project, the class moved mostly around the second floor and the wide stairs that connect the large classroom. While working in these spaces, we observed students engaging in three types of activities. The first type was related to Claire's direct instruction, involving setting the tasks for the day, presenting resources for the task, and answering students' questions and was regularly undertaken in the second floor. When setting these tasks, Claire asked students to gather together in one big circle facing her, and she had her laptop, a whiteboard and a screen in close proximity. The second type of activity was related to the presentation of students' work and was consistently located in the second floor. During those activities, the space functioned as a stage where students presented their draft and final work to their peers and teachers using the facilities of the screen and laptops. The third type of activity was situated on the staircase and on the second floor, and it was related to students' independent work. During these activities, students were free to move around unconstrained. For instance, students could sit on movable furniture and configure themselves within the physical space. Students 
could often make decisions regarding their tools, including whether to work with pen and paper, laptops, or both, and their proximity to other students.

The latter activities show evidence of students' agency during learning activities. Such agency was not only related to decision-making regarding their physical trajectories during learning lessons, but, we suggest, it was also related to students' cognitive involvement in the tasks. For instance, checking other students' work, collaborating with their peers, and having a sense of their comparative progress during learning lessons were facilitated by students' ability to move around the space. Such activities differ in the use of the space to activities described as type one and two in which students were expected to face the teacher (or the students when presenting) and to be quiet and attentive. As observed, the set design of the classroom space was flexible in accommodating structured activities along with promoting students' agency and independence. Figures 2 and 3 show the physical spaces where the project took place.

\subsubsection{Online space}

The online space consisted of a Learning Management System (LMS), a social network site (SNS), a Wi-Fi network and a 1:1 student laptop policy, which is a BYOD, and students' email accounts. The online space also included undefined locations where students use their laptops to enter into online portals (Gee 2004) such as the SNS, the LMS, and their email accounts. Those portals, accessible anytime and anywhere, enabled students to participate and follow up the online learning activities outside of the classroom. Undefined spaces where learning activities continued during the project involved, for instance, students' houses, the school library, the school yard, even the bus. Figure 4 illustrates the resources in the online space.

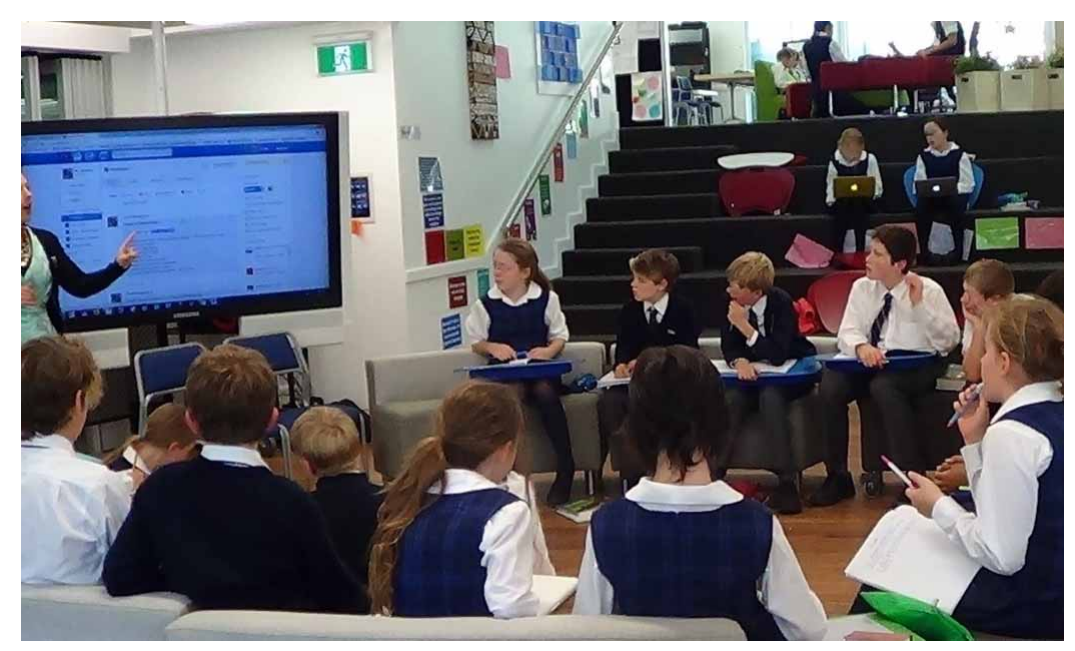

Figure 2. Physical space of the year 6 class. 


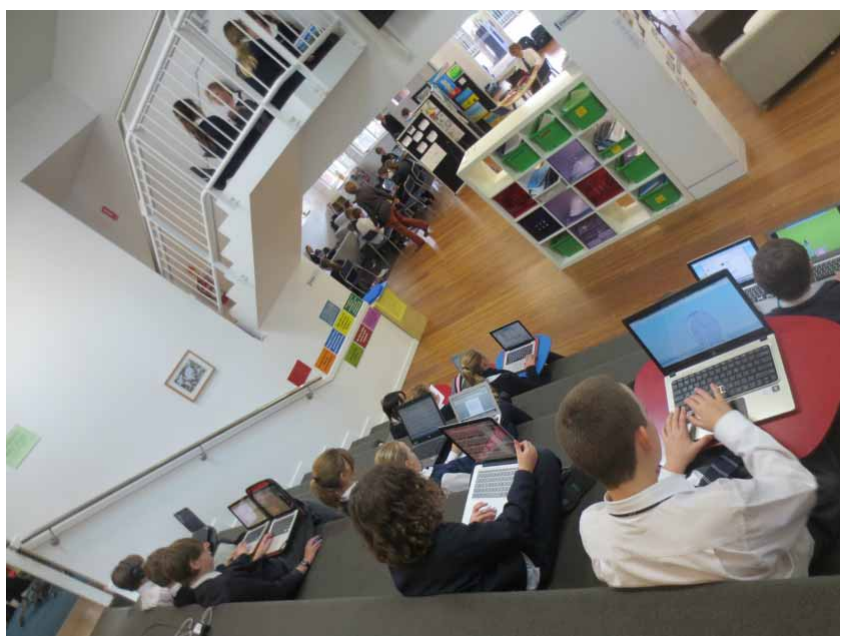

Figure 3. Physical space of the year 6 class: stairs used during independent learning.

The LMS functioned as a repository of information and a curriculum announcement board where teachers, students and parents could access information about the term schedule, tasks, and resources related to learning tasks. The information displayed was customised depending on who was accessing the LMS. Therefore, students, teachers, and parents saw different interfaces, each supporting the connection of relevant learning resources and the curriculum, to the agents involved in the process of schooling. During the project, the main function of this digital space was to archive relevant documentation related to theme parks tasks. Throughout the project, Claire uploaded resources that the students were able to access anytime and anywhere.

Edmodo was the SNS used in this classroom, which is a protected environment that 'offers teachers a collegial classroom management toolkit to use across their class periods' (Evans and Klilincm 2013, 4966). Its educational aim is what makes Edmodo different from commercial SNSs, such as Facebook (Ellison and Boyd 2013). For instance, specific features allow teachers to record grades, notify students about homework, keep calendars throughout the learning period, track students' progress on learning activities, and interact with their students. In addition, Edmodo allows students to privately or publicly submit homework or other information, receive alerts about deadlines for task submission, customise their student profile, and interact with their peers and teachers at any time and place. The layout of the interface allows users to

1:1 student laptop policy + Wifi network+ LMS (PETE) + Edmodo (SNS)

Figure 4. Online space and the digital resources included in the space. 
engage in social networking practices (Greenhow 2011) involving the design of their own profile; traversing, interacting and sharing content across the network in an asynchronous mode; and receiving notifications on assignments, due dates, and learning activities.

Interestingly, we observed that even though the activities in which students and the teacher engaged in the online space were spread over different devices, applications, and interfaces, often, the communication of pedagogical instruction happened through text-based asynchronous interactions on Edmodo. This is not surprising, given that this tool is specifically designed to promote dialogue between the agents in the network, yet it was often preferential for teaching purposes compared to synchronous face-to-face communication in the physical classroom.

\subsection{Navigating between the physical and the digital spaces}

A distinctive element in this learning network is that activities oscillated within and across online and physical settings, yet also over time. This echoes Hutchins (2000), who states that

cognitive processes may be distributed across the members of a social group, cognitive processes may be distributed in the sense that the operation of the cognitive system involves coordination between internal and external (material or environmental) structure, and processes may be distributed through time in such a way that the products of earlier events can transform the nature of later events. (1)

Whereas the use of the physical space was highlighted at the beginning and end of the project, activities in the online space acquired a noticeable predominance during the middle of the project. This does not mean that either of the spaces has an exclusive function when in their peak, rather there is a clear oscillation and interdependence between them. For instance, at the beginning of the project, the teacher emphasised the use of the physical space and material resources for engaging students. In turn, this affected the social and epistemic design that capitalises on face-to-face interactions aiming to stimulate students' prior knowledge and interest in the project. Over this period, no devices other than pen and paper were used. The focus was on students' attention on the teacher's discourse and on students' dialogue about their experiences with theme parks.

This contrasts with the intense use of laptops, Edmodo and the LMS when students initiated the development of their projects. In particular, students' use of the online connectivity and Internet allowed them to develop their projects. We will revisit this idea later in the analysis.

\subsection{Insights into teachers' practices}

Teachers' practices in this Networked Learning environment are strongly distributed across different spaces and tools. Instructional activities such as 
setting tasks and establishing time parameters were channelled through online portals, particularly through the use of Edmodo. This type of activity was possible due to the affordance of the SNS, which permits quick asynchronous interactions and works as a repository where students can revisit their work at a later time. For instance, after the first learning lesson, Claire uploaded a post on the Edmodo wall. In this post, she recapped the instructions explained during the lesson and the due day for submission. She also included a link where students could find a compilation of resources relevant for completing the weekly task about the theme park. She would repeat this action of distributing and reinforcing information over the three following weeks. The instruction on Edmodo is illustrated in Table 1.

During the project, Claire shared content-related resources on the LMS and used Edmodo to communicate to students where the resources about the theme park project could be found. By capitalising on the affordances of online tools, the teacher was able to design tasks that invited students to engage in active learning practices such as self-directed and independent learning. In contrast, a teacher within a conventional classroom environment would have had to invest time during the learning lesson to introduce the concepts needed for students' active work. The use of the online space in turn liberated time for the teacher to focus on personalised teaching. Our analysis suggests that the explicit

Table 1. Teacher's announcement on the Edmodo wall.

\section{History of Theme Parks}

Due 7 Jun 2013

1. Research the history of and present your findings on PP or Prezi of one of the following theme parks:

a) Sydney's Wonderland

b) Luna Park (circa 1980)

c) Old Sydney Town

2. Explain the theme of the park

3. Display some of the major attraction

4. Explain the reason for closure

5. Describe 3 lessons learned from this park's closure

We'll be using this resource for our Theme Park Imaginarium (Edcanvas | Theme Park Imaginarium Part 1, 4 Jun 2013)

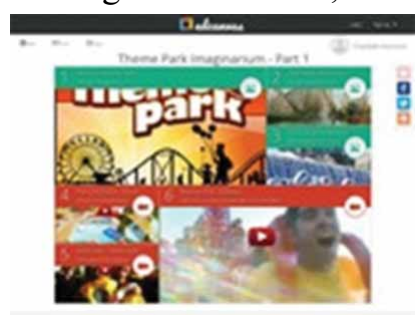


inclusion of online elements in the set design was intrinsically connected to an epistemic design that envisaged the redistribution of instructions and knowledge-related content, which then enabled other forms of instructional and learning activities in the physical context.

Along with the distribution of the teachers' instructions and content-related practices across spaces and tools, the nature of teachers' resources was also distributed over a variety of modes. The digital resources consisted of word documents as well as audio and video files; they also included multimodal, visual, aural, kineikonic and written modes (Curwood and Cowell 2011). Such digital resources were different in materiality and shape, extending the traditional use of pen and notebook in the classroom. By opening each of these resources, students were directed towards different digital spaces. Consequently, when Claire geared her teaching methods towards the digital, students were learning to use other resources different from conventional tools, such as pen and paper, worksheets, and notebooks. This led students to access alternative ways to think, share, and produce outputs in the classroom. As diSessa (2000) argues, the tools of written text and mathematic graphemes constitute the foundation of formal education and the elements with which to think, calculate, and represent ideas. Yet, in a digitally saturated era, other modes and tools for thinking enable young learners to effectively participate in society (Jenkins et al. 2009). Therefore, the findings suggest that the affordances of this set design and the tasks that the teacher designed in this Networked Learning environment augmented the range of students' cognitive possibilities (Figure 5).

According to the architecture of productive learning networks approach, ICT is used to support connections between agents and resources in a learning

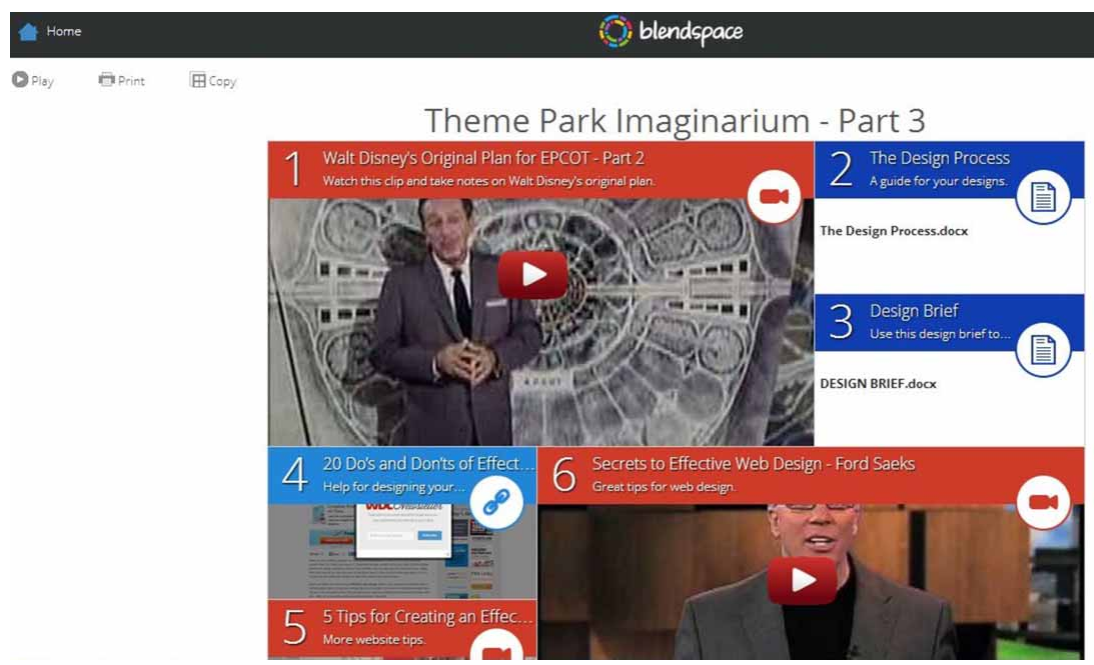

Figure 5. Edcanvas designed by the teacher during the theme park project. 
context. What differentiates this type of connection from formal face-to-face connections is that the epistemic transaction, including social interactions, production of outputs, verbal thinking, and collaboration, is highly distributed. The connections, and consequently the distributed knowledge among the relational elements in a learning environment, are constitutive in the definition of productive learning networks.

Another feature of teacher practices in this space was the distribution of knowledge across agents. In other words, the role of the teacher as the one who was in control of the management and the knowledge in the classroom was distributed across students and the teacher. The distribution of this function was facilitated due to the coexistence of a set design that offers a space for face-to-face communication in the classroom and Edmodo in the online space. For instance, whenever the teacher posted requirements, a number of questions from students were raised. Instead of waiting for a teacher's reply, what we observed consistently from the data is that students positioned themselves in a teacher's role and answered other students' questions. By checking students' questions, coming up with solutions, revisiting the information posted on the wall at different times, and elaborating and expanding on peers' answers, a pattern of reciprocal teaching (Palincsar and Brown 1986) appeared consistently across the activities. Here, it is clear how a set design that distributes elements in physical and online spaces facilitates reciprocal teaching among students and allows the knowledge to be redistributed among the agents participating in the project. Consequently, not only the teacher but also the students were able to share resources and knowledge about class activities. Table 2 illustrates this idea.

As the evidence above suggests, extending the opportunities for teachers to use digital resources not only affects teachers' repertoire of instruction but also offers opportunities for students to engage in reciprocal teaching and collaborative patterns of interactions affecting both teachers' and students' practices. In other words, the connections among agents and tools in a blended learning environment are rich and diverse, enhancing the process of distributed cognition across its elements. As Lave (1988) explains, 'Cognition is a complex social phenomenon ... distributed-stretched over not divided among-mind, body activity and culturally organized settings (which includes other actors)' (1).

A traditional classroom environment often limits the chances of social interaction due to several factors including, the length of the learning lesson, issues of knowledge and authority and the layout of the learning space; as a result, the social configurations of teaching and learning tend to be more hierarchical and teacher-centred (Collins and Halverson 2009). The findings of this study are consistent with research suggesting that the blending of face-to-face with an asynchronous digital environment allows each student's voice to be heard, gives less constraint in terms of time or space for students to think about their contribution, and increases students' self-expression (Warschauer 1996; Lazonder, Wilhelm, and Ootes 2003). 
Table 2. Students' interaction regarding task assignment on the Edmodo wall.

\begin{tabular}{|c|c|c|c|}
\hline Teacher and students interactions on Edmodo & Agents & Date & Type of interactions \\
\hline Theme Park Design & Teacher & $17 / 06 / 13$ & Task announcement \\
\hline \multicolumn{4}{|l|}{ Turn In Due 27 Jun 2013} \\
\hline \multicolumn{4}{|l|}{$\begin{array}{l}\text { Individually or in approved groups, students create an 'Australiana' themed } \\
\text { park concept website and model for future investors including the } \\
\text { following elements: }\end{array}$} \\
\hline \multicolumn{4}{|l|}{ Theme park name } \\
\hline \multicolumn{4}{|l|}{ Logo } \\
\hline \multicolumn{4}{|l|}{ Catch Phrase } \\
\hline \multicolumn{4}{|l|}{ Vision Statement } \\
\hline \multicolumn{4}{|l|}{ Indigenous considerations } \\
\hline \multicolumn{4}{|l|}{ Inclusive considerations } \\
\hline \multicolumn{4}{|l|}{ CIA considerations } \\
\hline What does 'vision statement' mean??:) & Student 1 & $18 / 06 / 13$ & Clarification \\
\hline vision statement??? & Student 2 & $18 / 06 / 13$ & Clarification \\
\hline what are all of these considerations & Student 3 & $18 / 06 / 13$ & Clarification \\
\hline Vision Statement is your vision for your theme park ... I think. & Student 4 & $24 / 06 / 13$ & Student's contribution \\
\hline I hope that answers your questions & Student 5 & $24 / 06 / 13$ & $\begin{array}{l}\text { Student's social } \\
\text { acknowledgment }\end{array}$ \\
\hline It is a statement about the goals and basic theme of your park. & Student 6 & $24 / 06 / 13$ & Student's contribution \\
\hline Ok thanks guys!:) & Student 4 & $24 / 06 / 13$ & $\begin{array}{l}\text { Student's social } \\
\text { acknowledgment }\end{array}$ \\
\hline What does the CIA meanplz respond ASAP & Student 7 & $25 / 06 / 13$ & Clarification \\
\hline $\begin{array}{l}\text { Christianity in action, it means what are you going to put in your } \\
\text { park that might be about God or whatever religion:) }\end{array}$ & Student 4 & $25 / 06 / 13$ & Student's contribution \\
\hline YAY, now I have finished all of the questions and onto my sketch up!:) & Student 4 & $26 / 06 / 13$ & $\begin{array}{l}\text { Student's social } \\
\text { acknowledgment }\end{array}$ \\
\hline
\end{tabular}

Theme park name

Logo

Catch Phrase

Vision Statement

Indigenous considerations

Inclusive considerations

CIA considerations

What does 'vision statement' mean??:)

$18 / 06 / 13$

what are all of these considerations

Vision Statement is your vision for your theme park ... I think.

Student 3

$18 / 06 / 13$

Student $4 \quad 24 / 06 / 13$

Student $5 \quad 24 / 06 / 13$

Student $6 \quad 24 / 06 / 13$

acknowledgment

It is a statement about the goals and basic theme of your park.

Student 4

Student's social acknowledgment

What does the CIA meanplz respond ASAP

Christianity in action, it means what are you going to put in your

Student 7

$25 / 06 / 13$

Clarification

YAY, now I have finished all of the questions and onto my sketch up!:)

Student 4

acknowledgment 


\subsection{Teachers' perceptions of technology in a learning network}

Rote memorisation, the dominance of the alphabetic print, decontextualised teaching and learning, and standardised assessment are still core features of much formal learning (Wenger 1998; Gee 2004; Honan 2012). However, what we observed in this networked environment is an alignment between teachers' ideas about student-centred approaches of learning and the belief that technology can be positively used to enhance students' learning. Claire shared:

I think I would die without it (technology) now. It is just an excellent tool that helps my students and myself to be much more clear about what I'm trying to communicate

I think technology allows the students and myself to access resources at any time, they don't have to be in the building or be at school to be able to access resources and to think about learning which actually guides them to my aim which is to be lifelong learners.

A number of studies have analysed technology integration in the classroom to support teachers' pedagogy (Ertmer 2005; Laurillard 2009; Curwood 2011). These scholars posit that technology integration in the classroom is far from being a unidirectional input-output process, and yet it has strong connections with less measurable elements as teachers' perceptions. In this regard, the interviews show progression towards an alignment between teaching and learning paradigms and the use of technology to enhance learning, yet it also makes clear the complexities involved in this process. A senior teacher of the school who has been working on the large open classroom for a few years commented:

Initially I resisted because my brain dynamic is very structured and ordered and I was concerned that I would not have the freedom of teaching the kids the way I wanted to teach them ... now looking back I love this ... I love kids taking ownership of their work, not the teachers taking ownership just imparting and handing out.

Acknowledging that students can often act in the role of more knowledgeable others implies a shift in how teachers perceive themselves and affects their notions of identity. This suggests that for some teachers, the idea of constructing their identities primarily as recipients and transmitters of knowledge is no longer applicable. As Collins and Halverson (2010) posit, 'Teachers serve as experts whose job is to pass on their expertise to students. Hence, most teachers do not like to see their authority challenged by students who find contradictory information or who ask questions beyond their expertise' (19). Similarly, Hirst (2004) suggests that educational behaviour based on knowledge transmission configures 'authoritarian social relations and recognizable teacher and student identities' (43). Unlike that unidirectional and hierarchical model of schooling, this Networked Learning environment expands the opportunities and the roles 
that agents in the space can play, echoing prior research (De Laat et al. 2007), yet at the same time, it might challenge teachers' identities. When asked 'How do you see yourself as a teacher?', Claire explained:

I think for me I try to focus on kids and their independence so for me I'm definitely more sort of a facilitator of thoughts. I like to guide students to the feeling that they have actually craft something themselves rather than I just completely input all of my knowledge into them. I don't feel like I'm the big end of all the knowledge. I definitely know that the constructive knowledge of a group is actually much more powerful than my personal knowledge.

When analysing Claire's own beliefs about technology unveiled over the interviews, as well as the practices and pedagogies she was implementing in the classroom, it is clear that her beliefs about integration technology in the classroom moved away from techno-centric approaches and a print-centric framework for assessment. This result is supported by the literature. For instance, Curwood (2014) suggests that cultural models, or everyday beliefs, directly influence teachers' approach to technology integration, instructional design, and assessment. Similarly, Ertmer and Ottenbreit-Leftwich (2010) state that teachers with student-centred beliefs tend to integrate technology in the classroom in more student-centred ways.

\subsection{Insights into students' learning activities}

Our analysis revealed some interesting patterns of students' learning activities. First, the set design of this learning space facilitates students' independent work, which allowed them to navigate the web, choose the resources they need for achieving the outcome of tasks, and in turn develop an individual trajectory. To successfully navigate blended spaces and employ various tools, students need a metacognitive awareness about their learning. These metacognitive processes, we argue, are often more complex than those associated with practices that are anchored solely in the physical space of the classroom as students have to make constant decisions about learning activities. This can be seen as potential opportunities for students to engage in self-directed and self-regulated learning, yet as we will shortly address it might also involve limitations.

Given the numerous decisions students have to make with regard to digital and analogous tools, physical and digital spaces, and time, metacognitive activities including planning, selecting, keeping clarity of the tasks and monitoring time for handing in tasks, adopt a rather multifaceted shape in this networked learning environment. For instance, Daniel (a pseudonym) sought to design a mind map that involved the following trajectory of actions: He first used Wikipedia and the Web to search for information about mind maps; he then used Edmodo to remind himself about instructions for the task initially set during the learning lesson and to see the questions his peers had posted about the task. Next, Daniel used pen and paper to register, externalise, and organise 
his ideas. Finally, he navigated the online space and used an online mind mapping tool to design and visualise his ideas about his theme park design; unlike physical tools, this permitted him to quickly try out different combinations by writing and deleting possible concepts to be added in his work.

The trajectories that Daniel and the rest of the students undertook during the theme park project enabled them not only to engage in independent learning but also to experience different patterns of thinking. This echoes Oviatt's (2013) research that found that interfaces capable of multiple representations, modalities, and linguistic codes can stimulate cognition and performance. Oviatt also found that digital tools stimulate higher levels of communication compared to analogous ones. Having access to multiple tools in the set design, along with a well-crafted epistemic design, stimulated the use of digital tools with which students could experiment to find new ways to represent content knowledge. We counted several applications that students were trying for this purpose such as Interactive Timeline, Trimble3D Warehouse, Aspyr, Sketch Express, Mind Map, Bubble-us, Stkyz.

The availability of multiple applications that students could access through the Internet to develop their projects might stimulate cognition, but, at the same time, might add complexity due to the constant decision-making process that students have to engage with when working in a blended environment of this type. Therefore, tools' affordances provide possibilities for cognitive expansion (Norman 1988), but if not managed correctly, they also can impact students' cognitive load (Hoffler and Leutner 2007).

A third pattern of students' learning practices was students engaging in new literacy practices (Lankshear and Knobel 2011). Unlike traditional instructional methods that often rely on pen and paper, individual seatwork and recitation scripts (Wells 2000), students were challenged in this space to use distributed tools, engage in different reading paths, create texts that are multimodal (Kress 2010), and keep track of meanings that count as new symbols for communications in the online space such as emoticons and visualisations. The set design also offered opportunities for students to be aware of audiences other than the teacher and therefore create new stages where students can share their work (Lammers, Magnifico, and Curwood 2014). Finally, the set design also allows students to experience new forms of interacting and authoring; in doing so, students are learning to cope with the fast speed of feedback that some digital tools (such as Edmodo) enable.

\section{Conclusion}

This case study illustrates how elements in the set design offer possibilities for teachers to innovate their teaching practices and are likely to affect students' learning activities. It also reminds us of the importance of supporting teachers to integrate new tools and learning processes with a focus on students' potential rather than on technology acquisition (Koehler and 
Mishra 2009). We observed that the role of the teacher, the relationship between student and teacher interactions, and the nature of students' own practices in this classroom differ from conventional school practices. We argue that the set design mediated these findings. The question posed by Hewitt and Scardamalia (1998) over a decade ago about what kinds of distribution enhance learning resonates with the shape of distribution in this blended school environment. In this example, physical and online spaces were used by the teachers in productive ways, thereby capitalising on affordances of digital tools to encourage students' independent and active learning. In turn, this affects their epistemic and social experiences.

Even though the analysis of this learning network shows productive results, blended classrooms require the availability of technical resources and support. It also requires the alignment of teachers' beliefs and practices. In closing, this study has provided evidence that suggests that activities in a networked learning environment are dependent upon both the set design and teachers' beliefs in leveraging students' learning practices.

\section{Acknowledgements}

We would like to acknowledge the school, teachers, and students who participated in this research. We also would like to thank the reviewers of this article for the constructive feedback.

\section{Funding}

Patricia Thibaut Páez's contributions to this article were financially supported by the Becas Chile scholarship programme sponsored by the Chilean government. Lucila Carvalho's contributions to this article were financially supported by the Australian Research Council [Laureate Fellowship Grant FL100100203].

\section{Notes on contributors}

Patricia Thibaut is a Ph.D. Candidate at the Centre for Research on Computer Supported Learning and Cognition at the University of Sydney. Her research focuses on learning, literacy, and mobile technologies across formal and informal spaces.

Jen Scott Curwood, Ph.D., is a senior lecturer in English education and media studies at the University of Sydney, where she is affiliated with the Centre for Research on Computer Supported Learning and Cognition. Her research focuses on literacy, technology, and teacher professional development.

Lucila Carvalho, Ph.D., is a postdoctoral research associate in the Centre for Research on Computer Supported Learning and Cognition at the University of Sydney. Lucila's research involves the analysis of complex learning systems in which technology plays a key role. Her interest is on understanding relationships between knowledge, human interaction and physical and digital resources; and how these combine to form productive learning networks. 
Alyson Simpson, Ph.D., is an associate professor in the Faculty of Education and Social Work at the University of Sydney. Her current research projects include work on the role of children's literature in education, the power of dialogic learning and the impact of digital technology on reading practices and pedagogy.

\section{References}

Attride-Stirling, J. 2001. "Thematic Networks: An Analytic Tool for Qualitative Research." Qualitative Research 1 (3): 385-405.

Barron, B. 2003. "When Smart Groups Fail." Journal of the Learning Sciences 12 (3): $307-359$.

Barron, B. 2006. "Interest and Self-Sustained Learning as Catalysts of Development: A Learning Ecology Perspective." 49 (4): 193-224.

Biggs, J., and C. Tang. 2007. Teaching for Quality Learning at University. Buckingham: Open University Press.

Bliuc, A., R. A. Ellis, P. Goodyear, and L. Piggott. 2011. "A Blended Learning Approach to Teaching Foreign Policy: Student Experiences of Learning Through Face-to-Face and Online Discussion and Their Relationship to Academic Performance." Computers \& Education 56 (3): 856-864.

Brown, J. S., A. Collins, and P. Duguid. 1989. "Situated Cognition and the Culture of Learning." Educational Researcher 18 (1): 32-42.

Burke, C. 2014. "Looking Back to Imagine the Future: Connecting with the Radical Past in Technologies of School Design." Technology, Pedagogy and Education 23 (1): 39-55.

Burke, C., P. Cunningham, and I. Grosvenor. 2010. "Putting Education in Its Place: Space, Place and Materialities in the History of Education." History of Education 39 (6): 677-680.

Burke, C., and I. Grosvenor. 2013. "The Steward Street School Experiment: A Critical Case Study of Possibilities.” British Educational Research Journal 39 (1): 148-165.

Carvalho, L., and P. Goodyear. 2014. The Architecture of Productive Learning Networks. New York: Routledge.

Collins, A., and R. Halverson. 2009. Rethinking Education in the Age of Technology. New York: Teachers College Press.

Collins, A., and R. Halverson. 2010. "The Second Educational Revolution: Rethinking Education in the Age of Technology." Journal of Computer Assisted Learning 26 (1): 18-27.

Curwood, J. S. 2011. "Teachers as Learners: What Makes Technology-Focused Professional Development Effective?" English in Australia 46 (3): 68-75.

Curwood, J. S. 2014. "English Teachers' Cultural Models about Technology: A Microethnographic Perspective on Professional Development." Journal of Literacy Research 46 (1): 9-38.

Curwood, J. S., and L. L. Cowell. 2011. "iPoetry: Creating Space for New Literacies in the English Curriculum." Journal of Adolescent and Adult Literacy 55 (2): $110-120$.

De Laat, M., V. Lally, L. Lipponen, and R.-J. Simons. 2007. “Online Teaching in Networked Learning Communities: A Multi-Method Approach to Studying the Role of the Teacher." Instructional Science 35 (3): 257-286.

Derry, S. J., R. D. Pea, B. Barron, R. A. Engle, F. Erickson, R. Goldman, R. Hall, et al. 2010. "Conducting Video Research in the Learning Sciences: Guidance on Selection, Analysis, Technology, and Ethics." The Journal of Learning Sciences 19 (3): 3-53. 
diSessa, A. 2000. Changing Minds: Computers, Learning and Literacy. Cambridge, MA: MIT Press.

Ellison, N. B., and D. Boyd. 2013. "Sociality Through Social Network Sites." In The Oxford Handbook of Internet Studies, edited by W. H. Dutton, 151-172. Oxford: Oxford University Press.

Ertmer, P. 2005. "Teacher Pedagogical Beliefs: The Final Frontier in Our Quest for Technology Integration?" Educational Technology Research and Development 53 (4): 25-39.

Ertmer, P. A., and A. T. Ottenbreit-Leftwich. 2010. "Teacher Technology Change: How Knowledge, Confidence, Beliefs, and Culture Intersect." Journal of Research on Technology in Education 42 (3): 255-284.

Evans, R. T., and E. Klilincm. 2013. "Creating 21st Century Learners: Edmodo in the Social Studies Classroom." In Society for Information Technology \& Teacher Education International Conference (SITE), edited by Ron McBride and Michael Searson, 4965-4970. Chesapeake, VA: AACE.

Gee, J. P. 2004. Situated Language and Learning: A Critique of Traditional Schooling. New York: Routledge.

Goodyear, P. 2000. "Environments for Lifelong Learning: Ergonomics, Architecture and Educational Design." In Integrated and Holistic Perspectives on Learning, Instruction \& Technology: Understanding Complexity, edited by J. M. Spector and T. Anderson, 1-18. Dordrecht: Kluwer.

Goodyear, P. 2005. "Educational Design and Networked Learning: Patterns, Pattern Languages and Design Practice." Australasian Journal of Educational Technology 21 (1): 82-101.

Goodyear, P., S. Banks, V. Hodgson, and D. McConnell. 2004. Advances in Research on Networked Learning. Dordrecht: Springer.

Goodyear, P., and L. Carvalho. 2014. "The Analysis of Complex Learning Environments." In Rethinking Pedagogy for a Digital Age: Designing for 21st Century Learning, edited by H. Beetham and R. Sharpe, 2nd ed., 49-63. New York: Routledge.

Greenhow, C. 2011. "Online Social Networks and Learning." On the Horizon 19 (1): 4-12.

Hewitt, J., and M. Scardamalia. 1998. "Design Principles for Distributed Knowledge Building Processes." Educational Psychology Review 10 (1): 75-96.

Hirst, E. 2004. "Diverse Social Contexts of a Second-Language Classroom and the Construction of Identity." In Spatializing Literacy Research and Practice, edited by K. Leander and M. Sheehy, 39-66. New York: Peter Lang.

Hoffler, T. N., and D. Leutner. 2007. "Instructional Animation Versus Static Pictures: A Meta-Analysis." Learning and Instruction 17 (6): 722-738.

Honan, E. 2012. "A Whole New Literacy." Australian Journal of Language and Literacy 35 (1): 82-98.

Hutchins, E. 2000. Distributed Cognition. IESBS, 1-10. http://www.artmap-research. com/wp-content/uploads/2009/11/Hutchins_DistributedCognition.pdf

Jenkins, H., R. Purushotma, K. Clinton, M. Weigel, and A. Robison. 2009. Confronting the Challenges of Participatory Culture: Media Education for the 21st Century. http://newmedialiteracies.org/files/working/NMLWhitePaper.pdf

Koehler, M. J., and P. Mishra. 2009. "What Is Technological Pedagogical Content Knowledge?" Contemporary Issues in Technology and Teacher Education 9 (1), 60-70.

Kress, G. 2010. Multimodality. A Social Semiotic Approach to Contemporary Communication. London: Routledge. 
Lammers, J. C., A. M. Magnifico, and J. S. Curwood. 2014. "Exploring Tools, Places, and Ways of Being: Audience Matters for Developing Writers." In Exploring Technology for Writing and Writing Instruction, edited by K. E. Pytash and R. E. Ferdig, 186-201. Hershey, PA: IGI Global.

Lankshear, C., and M. Knobel. 2011. New Literacies: Everyday Practices and Social Learning. New York: Open University Press.

Laurillard, D. 2009. "The Pedagogical Challenges to Collaborative Technologies." Journal of Computer-Supported Collaborative Learning 4 (5): 5-20.

Lave, J. 1988. Cognition in Practice: Mind, Mathematics, and Culture in Everyday Life. Cambridge: Cambridge University Press.

Lazonder, A. W., P. Wilhelm, and S. A. W. Ootes. 2003. "Using Sentence Openers to Foster Student Interaction in Computer-Mediated Learning Environments." Computers \& Education 41 (3): 291-308.

Lenhart, A., M. Madden, A. R. Macgill, and A. Smith. 2007. "Teens and Social Media." Pew/Internet \& American Life Project. http://www.pewinternet.org/ 2007/12/19/teens-and-social-media/

Lenhart, A., K. Purcell, A. Smith, and K. Zickuhr. 2010. "Social Media and Mobile Internet Use among Teens and Young Adults." Pew Internet \& American Life Project. http://www.pewinternet.org/2010/02/03/social-media-and-young-adults/

Means, B., R. Murphy, and M. Baki. 2013. "The Effectiveness of Online and Blended Learning: A Meta-Analysis of the Empirical Literature." Teachers College Record 115 (3): $1-47$.

Mehan, H. 1979. Learning Lessons: Social Organization in the Classroom. Cambridge, MA: Harvard University Press.

Norman, D. 1988. The Psychology of Everyday Things. New York: Basic Books.

Oviatt, S. 2013. The Design of Future Educational Interfaces. London: Routledge.

Palincsar, A. M., and A. L. Brown. 1984. "Reciprocal Teaching of ComprehensionFostering and Monitoring Activities." Cognition and Instruction 1 (2): 117-175.

Picciano, A. 2009. "Blending with Purpose: The Multimodal Model." Journal of Asynchronous Learning Networks 13 (1): 7-18.

Sharpe, R., G. Benfield, and G. Roberts. 2006. The Undergraduate Experience of Blended e-Learning: A Review of UK Literature and Practice. London: Higher Education Academy.

Vygotsky, L. S. 1981. "The Genesis of Higher Mental Functions.” In The Concept of Activity in Soviet Psychology, edited by J. V. Wertsch, 144-188. Armonk, NY: M. E. Sharp.

Warschauer, M. 1996. "Comparing Face-to-Face and Electronic Discussion in the Second Language Classroom." CALICO Journal 13 (2-3): 7-26.

Wells, G. 2000. "Dialogic Inquiry in Education. Building on the Legacy of Vygostky." In Vygotskian Perspectives on Literacy Research. Constructing Meaning Through Collaborative Inquiry, edited by C. Lee and P. Smagorinsky, 51-85. New York: Cambridge University Press.

Wenger, E. 1998. Communities of Practice: Learning, Meaning and Identity. Cambridge, MA: Cambridge University Press.

Wertsch, J. 1998. Mind as Action. New York: Oxford University Press. 